\title{
Establishment of an Endangered species on a private nature refuge: what can we learn from reintroductions of the bridled nailtail wallaby Onychogalea fraenata?
}

\author{
Lisa Kingsley, Anne Goldizen and Diana O. Fisher
}

\begin{abstract}
Translocation and reintroduction are used to reduce extinction risk associated with a small population and range size in threatened mammal species. We evaluated the outcome of a reintroduction of the bridled nailtail wallaby Onychogalea fraenata to Avocet Nature Refuge, a private refuge in central Queensland, Australia. This macropod was also reintroduced to Idalia National Park in western Queensland in 1996 and occurs in one natural population in central Queensland. We estimated population growth, adult and juvenile survival, and distribution changes since the last release of $O$. fraenata to Avocet in 2005, and evaluated female reproductive success and health. Although animals were in good condition, population size was a tenth of that of the 1996 Idalia reintroduction reported after 3 years and, unlike at Idalia, juvenile survival at Avocet was low. The likely causes are consistent with predictors of translocation and reintroduction failures in mammals. These are predation, the small number of individuals in each release, the likely suboptimal health status of reintroduced individuals, drought, and possibly lack of dispersal from the small area of preferred habitat. The lessons of this reintroduction are that future attempts are likely to have the best chance of success if they occur in nondrought years, at sites with large, non-fragmented areas of brigalow forest, involve the release of large groups of animals together, and are accompanied by intensive, longterm baiting to control introduced predators.
\end{abstract}

Keywords Australia, Avocet Nature Refuge, bridled nailtail wallaby, ex situ conservation, Macropodidae, Onychogalea fraenata, reintroduction, translocation

\section{Introduction}

A bout a third of all modern mammal extinctions have occurred in Australia during the last 150 years

\footnotetext{
LisA KingsLeY*, ANNE Goldizen and DiAna O. Fisher (Corresponding author) School of Biological Sciences, Goddard building (8), The University of Queensland, School of Biological Sciences, St Lucia 4072, Queensland, Australia. E-mail d.fisher@uq.edu.au

${ }^{*}$ Current address: 7610 Ridgecrest Drive, Alexandria, Virginia, 22308, USA

Received 18 November 2010. Revision requested 25 January 2011.

Accepted 15 March 2011.
}

(Johnson, 2006; IUCN, 2010). Major causes of decline have included habitat change from land degradation by livestock, particularly sheep, and introduced predators such as feral cats Felis catus and red foxes Vulpes vulpes (Fisher et al., 2003). Because many remaining threatened mammal populations are small and geographically restricted, in situ management strategies to halt further declines may not be enough to recover populations of many species in the long term. We also need to establish new populations to distribute the risk of chance disasters (Seddon et al., 2007).

Translocation and reintroduction are common conservation strategies, especially for mammals and birds (Fischer \& Lindenmayer, 2000; Armstrong \& Seddon, 2008). Crossspecies comparative studies show that reintroductions often fail to establish self-sustaining populations (Veltman et al., 1996; Wolf et al., 1996, 1998; Fischer \& Lindenmayer, 2000). Seddon (1999) and Seddon et al. (2007) suggested that success should be measured by the survival and successful reproduction of the released animals and their offspring, and the persistence of a self-sustaining population. However, the success of translocations is not often assessed, especially after the initial period of establishment (Seddon et al., 2007). Some of the most important factors associated with successful translocations and reintroductions are: (1) sufficient knowledge of the natural history of the species to inform the choice of a suitable site, (2) knowledge of the cause of decline and elimination of this threat at the reintroduction site (Wolf et al., 1996; Fischer \& Lindenmayer, 2000), (3) selection of appropriate age classes, sex ratios and healthy individuals for release (Pople et al., 2001; Robert et al., 2004; Letty et al., 2007), and (4) establishing populations in the core of a species' historical range (Wolf et al., 1998).

The bridled nailtail wallaby Onychogalea fraenata is a medium sized ( $4-8 \mathrm{~kg})$, solitary, nocturnal species that now inhabits $<1 \%$ of its former range and is categorized as Endangered on the IUCN Red List (McKnight, 2008). Possible causes of decline include vegetation clearing (resulting in $<10 \%$ of the species' original habitat remaining), introduced predators (red foxes and feral cats), and vegetation degradation by introduced herbivores, particularly sheep and cattle, and perhaps rabbits (Gordon \& Lawrie, 1980). O. fraenata was presumed to be extinct from c. 1932 until its rediscovery in 1973 on a cattle property in central Queensland (Gordon \& Lawrie, 1980). The 
property was purchased by the Queensland National Parks Service and is now Taunton National Park (Scientific), containing the sole remaining wild population of this species. The population was estimated to be $>1,000$ during 1986-1990 (Tierney, 1985; Evans, 1992) but declined following a severe drought in 1992-1994 to < $<00$ (Fisher et al., 2000, 2001), and has continued to decline in size and distribution. Reasons for the current decline at Taunton National Park (Scientific) are unknown but are probably combinations of changing vegetation reducing the availability of preferred food and shelter, increased predation by dingoes and cats during droughts, and chance effects of small population size (Fisher et al., 2000, 2001).

A reintroduction of bridled nailtail wallabies to Idalia National Park in western Queensland commenced in 1996. During 1996-1999 133 individuals sourced from a captive breeding colony and from the Taunton population were released. There was intensive predator control, monitoring to detect predator incursions, establishment of a fenced breeding colony, release of animals born on the site as well as wild-born animals, and regular monitoring (Pople et al., 2001). The reintroduction was considered to be a success in 2001 because the population had increased to 400 (Pople et al., 2001). In 2001-2005 there was a further reintroduction, at Avocet Nature Refuge. This is an area of privately-owned land, designated as a nature refuge under a Voluntary Conservation Agreement with the Queensland government. This refuge contains c. 90 cattle and is c. $120 \mathrm{~km}$ south-west of Taunton National Park (Scientific). The aim of the study reported here was to determine whether the reintroduction at Avocet Nature Refuge has succeeded in establishing a selfsustaining population.

\section{Study area}

The 565 ha Avocet Nature Refuge (Fig. 1) contains suitable habitat (see below) and falls within the historical range of O. fraenata. Mean annual rainfall is $574 \mathrm{~mm}$, lower than at Taunton National Park (Scientific) $(692 \mathrm{~mm})$ but higher than at Idalia $(451 \mathrm{~mm})$. The beginning of the study (20012003), when most of the releases took place, was a time of severe drought in central Queensland (Fig. 2). Rainfall increased throughout the study, and 2007 and 2008 were years of above-average rainfall.

Vegetation structure and floristics in Avocet Nature Refuge are similar to those at Taunton National Park (Scientific), including brigalow Acacia harpophylla, the main habitat of $O$. fraenata. Feral cats, dingoes Canis lupus dingo and red foxes occur in Avocet. There is no predator baiting o monitoring but during 2004-2008 51 cats and five foxes were shot on the refuge by Hunting and Conservation Queensland, a volunteer organization that visits twice per year.

In 14 releases from 2001 to 2005166 O. fraenata were reintroduced to Avocet (Table 1). These wallabies came from

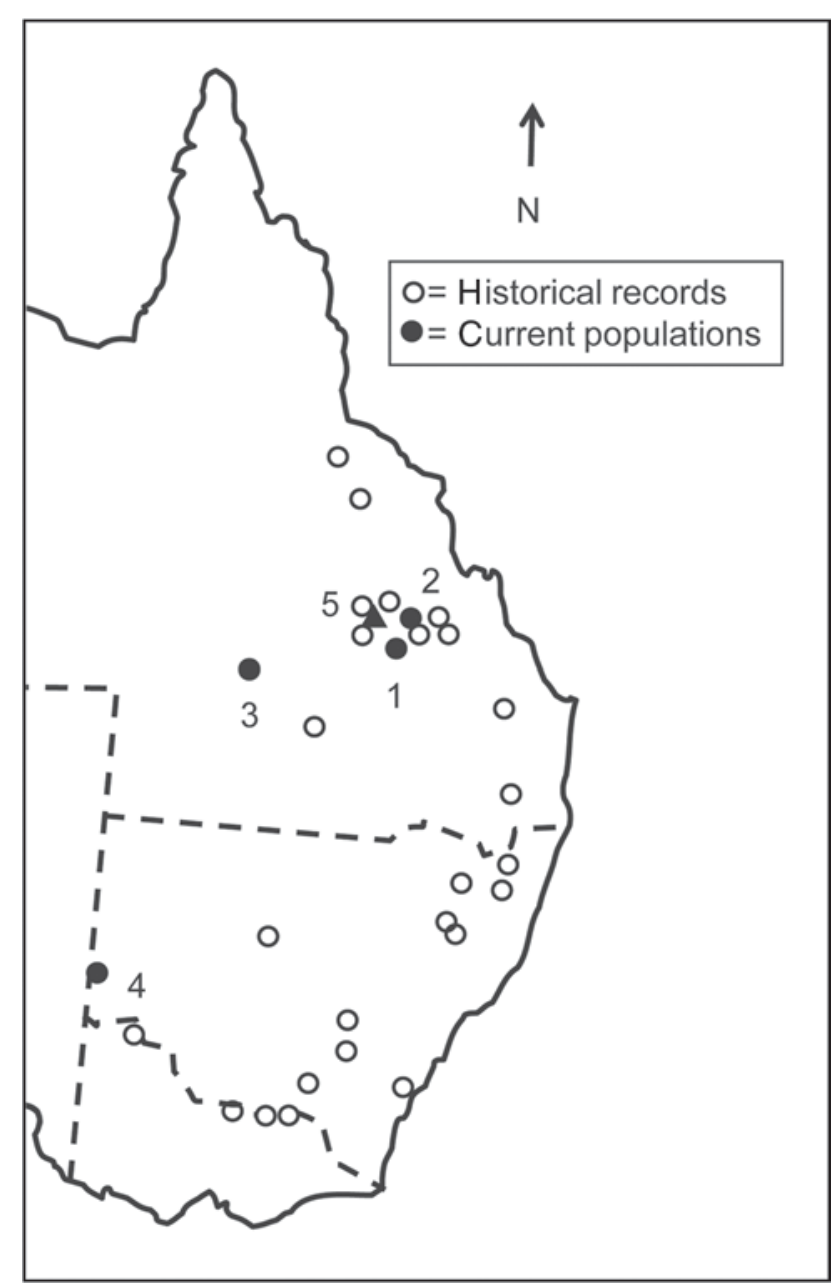

FIG. 1 Map of the eastern third of Australia showing locations of historical records of the bridled nailtail wallaby Onychogalea fraenata, and current populations at (1) Avocet Nature Refuge,

(2) Taunton National Park (Scientific), the sole wild population,

(3) Idalia National Park, and (4) Scotia Sanctuary. Gregory mine site is indicated by a black triangle (5). Adapted from LundieJenkins \& Lowry (2005). Points indicating the location of sites are not to scale.

a captive breeding enclosure (Gregory mine site, in central Queensland, founded from 16 captive-bred animals in 1997). Ninety-seven wallabies were moved directly from the Gregory Mine enclosure to two predator-proof holding pens $(50 \times 50 \mathrm{~m}), 1 \mathrm{~km}$ apart, for 1 week before release, between 2001 and 2003 (Table 1). The remaining 69 wallabies had parasite infestations and were in poor health (Old et al., 2009) and were treated at a nearby animal care facility (Marlborough) before release.

\section{Methods}

\section{Spotlighting}

We surveyed O. fraenata at Avocet in May and July 2008. We refer to the data collected during these surveys as this 


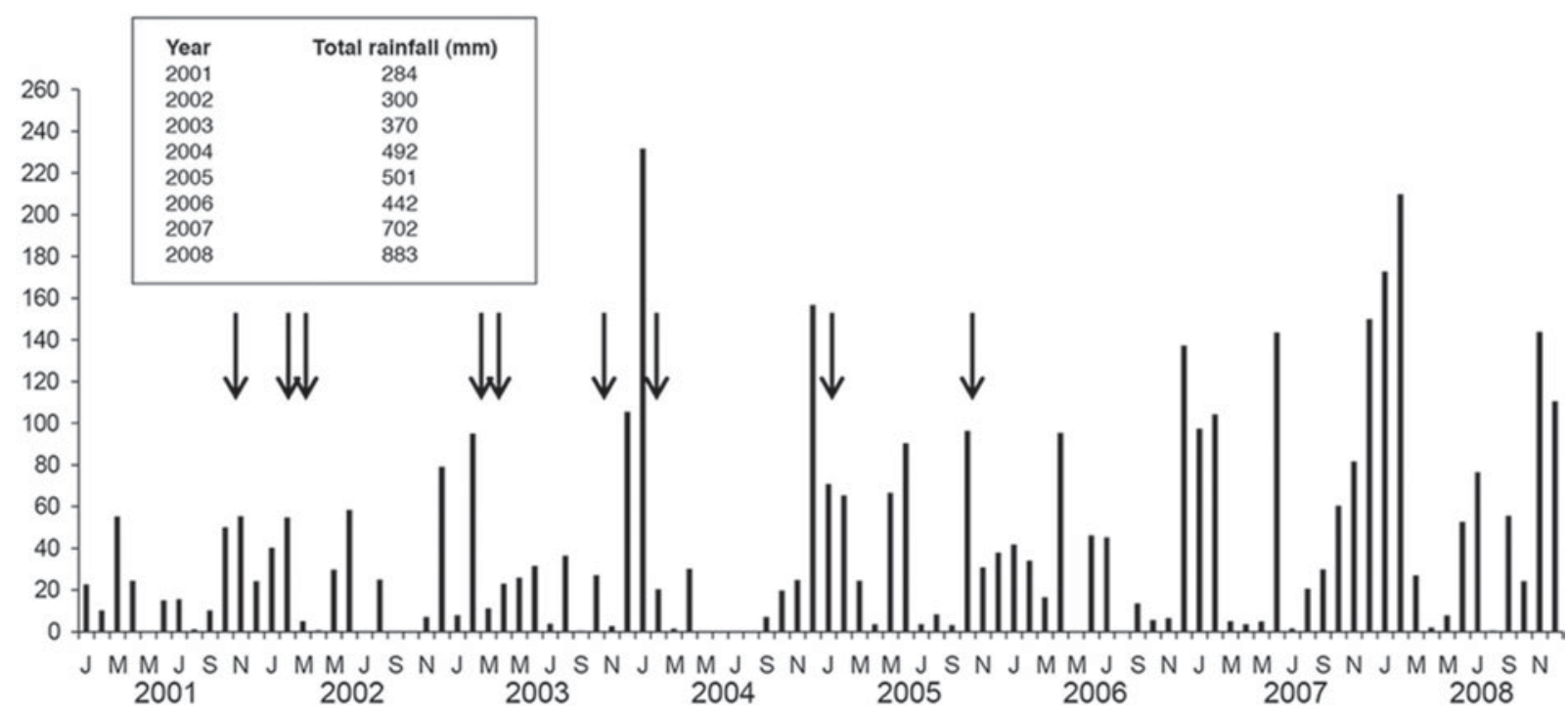

FIG. 2 Monthly rainfall record between January 2001 and December 2008 at Emerald, c. 30 km from Avocet Nature Refuge (Fig. 1). Arrows show months in which O. fraenata were released. Mean annual rainfall at Emerald is slightly less than at Avocet (558 mm). The study period began in a time of severe drought; cumulative rainfall deficiency in central Queensland was severe in 2002, Avocet and surrounding areas experienced $<5 \%$ of the historical rainfall mean in 2002-2003 (BOM, 2003). Annual rainfall increased during the study period, and 2007 and 2008 were years of above-average rainfall.

study and the data previously collected by Queensland Department of Environment staff (2005-2007) as previous studies. During this study we conducted transect surveys by spotlighting from a vehicle for 12 nights on each sampling occasion, to estimate population size, density and distribution. Surveys were conducted between 20.00 and 23.00, when $O$. fraenata is active, in a vehicle travelling at $10 \mathrm{~km} \mathrm{~h}^{-1}$ along $5.6 \mathrm{~km}$ of unsealed tracks. This is the same sampling method as that of Fisher et al. (2000) and Pople et al. (2001), who showed by radio-tracking that $O$. fraenata readily use the edges of blocks of forest, including unsealed tracks, which often have pasture growing on and along them. It was not possible to use walked transects because $O$. fraenata flee from people on foot, whereas they usually ignore vehicles (Evans, 1992; Fisher et al., 2000).

We used eight transects, in all forest types throughout the Refuge, including brigalow regrowth and mature brigalow forest. Six transects were $800 \mathrm{~m}$ long and two $400 \mathrm{~m}$ long (the length of available tracks). These transects covered most available tracks in each forest type. To determine an appropriate strip width for density estimation we measured the distance from the track edge to each $O$. fraenata sighted, using a tape measure.

\section{Trapping and handling}

To estimate population size and health we trapped O. fraenata using 45 wire cage traps $(380 \times 380 \times 760 \mathrm{~mm}$, Mascot Wire Works, Sydney, Australia) on a total of 22 nights during May and July 2008. Traps were placed throughout the trap sites, baited with lucerne hay, checked
TABLE 1 Dates and numbers of Onychogalea fraenata reintroduced at Avocet Nature Refuge (Fig. 1). All wallabies originated from the Gregory mine site breeding facility (Fig. 1).

\begin{tabular}{llccr}
\hline Release & Date & Males & Females & Total \\
\hline 1 & 1 Dec. 2001 & 7 & 5 & 12 \\
2 & 8 Mar. 2002 & 7 & 5 & 12 \\
3 & 20 Apr. 2002 & 7 & 5 & 12 \\
4 & 17 Mar. 2003 & 7 & 8 & 15 \\
5 & 7 Apr. 2003 & 8 & 6 & 14 \\
6 & 28 Apr. 2003 & 3 & 6 & 9 \\
7 & 17 Dec. 2003 & 10 & 6 & 16 \\
8 & 18 Dec. 2003 & 5 & 1 & 6 \\
9 & 1 Feb. 2004 & 0 & 1 & 1 \\
10 & 4 Feb. 2005* & 20 & 0 & 20 \\
11 & 5 Feb. 2005* & 20 & 0 & 20 \\
12 & 18 Feb. 2005* & 0 & 12 & 12 \\
13 & 25 Feb. 2005* & 0 & 7 & 7 \\
14 & 15 Nov. 2005* & 4 & 6 & 10 \\
Total & & 98 & 68 & 166 \\
\hline
\end{tabular}

${ }^{\star}$ Indicates releases where wallabies were moved from the Gregory mine site to Marlborough for rehabilitation prior to being released at Avocet.

every 3 hours, and closed between 21.00 and 06.00. Trap sites were concentrated within a $2 \mathrm{~km}^{2}$ area of the Refuge, based on the distribution of sightings in spotlighting surveys. Fifteen additional traps were also placed in other areas of potential habitat. Some traps were moved each night because there were more trapping locations than traps. Trapping techniques used by Queensland Department of Environment staff from October 2005 to March 2008 were similar (trapping sessions were 1 week each) but the number 
of traps set each night varied between and within trapping sessions, from five to 15 each night.

Trapped $O$. fraenata were placed in hessian bags, sexed and weighed to the nearest $50 \mathrm{~g}$ using a $10 \mathrm{~kg}$ spring balance. We measured head and foot length (heel to base of nail) using callipers, to the nearest $\mathrm{mm}$. New wallabies were individually tagged with a unique microchip (Trovan, Keysborough, Australia). Female wallabies were checked for lactating teats and pouch young, and the sex, pes (hind foot) length and teat position were recorded for all pouch young.

All adult wallabies were scored on body condition and general health. Young wallabies with pes lengths $<124 \mathrm{~mm}$ for males and $<120 \mathrm{~mm}$ for females were excluded from the analysis of overall body condition (Pople et al., 2001). We calculated health index scores of trapped wallabies using a similar method as Fisher et al. (2000, 2001). The highest score was 5 (extremely good health) and individuals lost half a point for each of the following: heavy ectoparasite load, drooling, reduced muscle mass and reduced fat at the base of the tail (Lapidge, 2006), dehydration assessed by poor skin elasticity at the base of the neck, poor coat condition, sores in mouth, and opaqueness in eyes. Health indices were based on the first capture per trip. Condition was calculated as residual body mass divided by leg length.

\section{Assessment of female breeding success}

Females breed continuously and give birth the day after the previous young has permanently left the pouch (i.e. is no longer carried but still suckles by putting its head in the pouch; Johnson, 1997; Hendrikz \& Johnson, 1998). We estimated the reproductive rate of females by estimating inter-birth intervals from birth dates of pouch young of females that were trapped more than once during trips in March and July, and recording the presence or absence of a second lactating teat in all mature females ( $>6$ months) with pouch young $<55$ days old (Johnson, 1997). Presence indicates that the female is breeding continuously as expected, and has a live young-at-foot in addition to the small pouch young, and absence indicates that she has lost an infant (Fisher \& Goldizen, 2001). We did not include primiparous females in this calculation (easily recognized by pouch appearance and body size; Fisher, 1999). Estimated ages and birth dates of pouch young were calculated from pes length (Hendrikz \& Johnson, 1998).

\section{Data analyses}

Densities at Idalia and Taunton National Parks have been estimated with distance sampling (Fisher et al., 2000; Pople et al., 2001) but we observed too few individuals (14) to use this method. We therefore estimated density by dividing the total number of $O$. fraenata seen each night by the area sampled by transects $\left(2 \mathrm{~km}^{2}\right)$. To find this area we estimated the effective strip width to be $40 \mathrm{~m}$ on either side of the track.

We collated individual capture records for each trapping trip between 2005 and 2008, to estimate population size and yearly survival. There were eight capture sessions. Sixty-six individual adults were caught and microchipped. The captures per session were: Trip 1 (October 2005) 15 captures, Trip 2 (April 2006) 8 captures, Trip 3 (September 2006) 12 captures, Trip 4 (April 2007) 9 captures, Trip 5 (September 2007) 12 captures, Trip 6 (March 2008) 8 captures, Trip 7 (May 2008) 25 captures, and Trip 8 (July 2008) 31 captures. We used MARK (White \& Burnham, 1997) to estimate population size for each trapping session. We only included independent adults in the models. This method assumes that the population is closed during the relatively brief period of sampling within each trip (with no immigration, emigration, births or deaths). We compared the fit of models allowing population size and capture probability to vary with time and between individuals, with models having time and individual-invariant (constant) population sizes and capture probabilities.

We also used MARK to model yearly survival and capture probabilities. We compared the fit of models allowing both survival and capture probability to vary with time, with models having time-invariant (constant) survival and/or capture probabilities. For both survival and population size estimates we used the most general model to generate an estimate for the data dispersion parameter $\hat{c}$. We estimated $\hat{c}$ using the median $\hat{c}$ approach in MARK. The survival data were underdispersed and most sessions of the population size data were overdispersed. We therefore used the value of median $\hat{c}$ to adjust the quasi-Akaike information criterion for small sample sizes (QAICc) in MARK. We compared model fit using this adjusted information criterion where the best-fit model had the lowest QAICc value.

We calculated body condition indices as residuals from a regression of body mass on leg length (Fisher, 1999; Fisher et al., 2000; Pople et al., 2001) for adults. Body mass and leg length measurements, and condition and health scores were averaged per year for individuals captured more than once, to ensure statistical independence. Sexes were analysed separately. A Spearman rank correlation was calculated between health index scores and condition indices. We tested associations between body mass and leg length with linear regression, using $R$ v. 2.10.0 (R Development Core Team, 2009).

\section{Results}

\section{Population size and density}

The $14 O$. fraenata seen during spotlighting surveys were only on the two transects within brigalow forest, suggesting 
that the population is confined to a small area of brigalow woodland $\left(\right.$ c. $\left.2 \mathrm{~km}^{2}\right)$, less than half of the total area of the Refuge, and has not spread beyond the habitat surrounding the two original release sites. Estimates of density from transect sampling were $7.8-39.1 \mathrm{~km}^{-2}$, giving a mean density estimate of $19.0 \pm \mathrm{SE} 10.1 \mathrm{~km}^{2}$. The mean population estimate from line-transect counts was 38 , based on the area of c. $2 \mathrm{~km}^{2}$ in which $O$. fraenata was found.

The total number of $O$. fraenata trapped in $2008(\mathrm{n}=37)$ was higher than in surveys of the population in 2005-2007. Approximately equal numbers of males and females were trapped in this study (20 and 17, respectively). Twenty-eight of the $37(76 \%)$ trapped did not have microchips (13 females and 15 males). Four individuals that were released as part of the reintroduction in 2005 were captured. A total of five $O$. fraenata born at Avocet following the reintroduction were captured and had been microchipped during trapping sessions prior to 2008. There was some evidence of an increase in population in the last two capture sessions of 2008 (Fig. 3). Population estimates from mark-recapture analysis in this study were 26 (95\% confidence limits, CL, 26-33) in May and 31 (95\% CL 31-41) in July.

\section{Adult survival rate}

The model with the most support was one of timedependent survival probability and variation in capture success over time (Table 2). The AICc weight for the bestfit model was close to 1 , and the next best model $(\Delta \mathrm{QAICc}=17)$ was 0.0002 . Yearly survival varied from $18 \%$ in October-April (the wet/austral summer season) of 2006 and 2007 (Fig. 4), to $>90 \%$ during April-October 2007 and March-May 2008. Capture probabilities varied widely and were $<40 \%$ in half of the sessions, although capture probability in May 2008 was $87 \pm$ SE $8 \%$ (Fig. 4).

\section{Analysis of body condition measures}

Health index values were significantly correlated with condition indices calculated from body mass relative to leg length in both sexes (Spearman's rank correlation $\rho=0.806, P=0.0022$, for females, $\mathrm{n}=17 ; \rho=0.628$, $\mathrm{P}=0.0036$, for males, $\mathrm{n}=20$ ). The levels of tick and ear mite infestations were low to moderate and decreased during the study period. No individuals during this study received a health index score below 3 . In 2008 the mean body mass was $3,710 \pm$ SE $160 \mathrm{~g}$ for adult females and 4,307 \pm SE $240 \mathrm{~g}$ for adult males.

\section{Reproductive rate and evidence of offspring mortality}

Fifteen females of reproductive age (non-primiparous) were captured in 2008; fourteen (93\%) of these had pouch young.

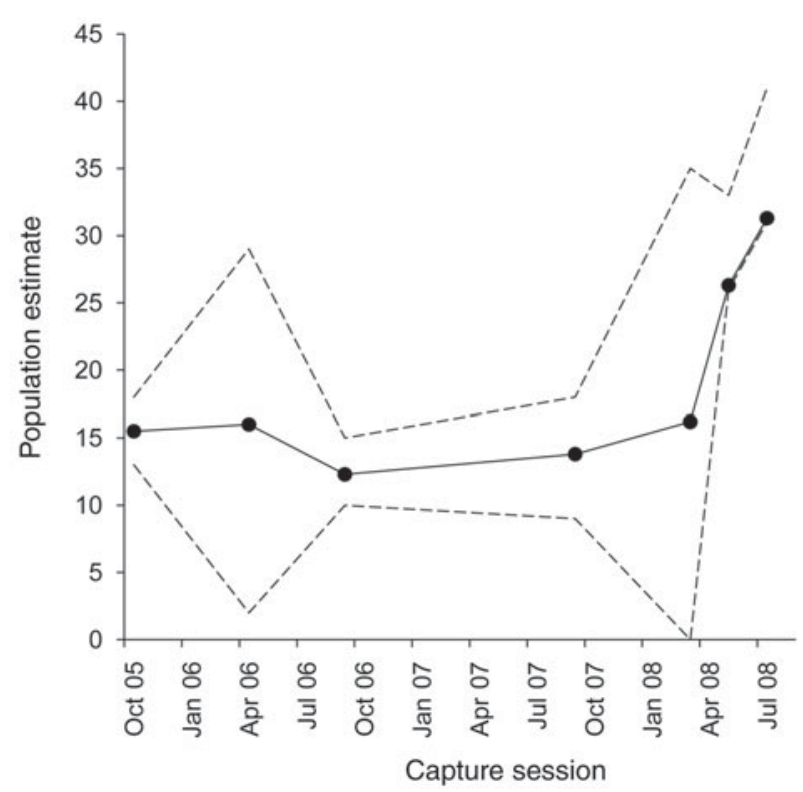

FIg. 3 Estimates of mean population size of O. fraenata at Avocet Nature Refuge, with upper and lower 95\% confidence intervals (dashed lines), from October 2005 to July 2008. Data for April 2007 could not be modelled because of the small number of captures.

Four females carried two different pouch young over the study period and therefore a total of 18 young were recorded. Only one female may have had a reproductive failure (nonconception, or death of a newborn pouch young), suggesting a maximum reproductive failure rate of $12.5 \%$ for this population. However, the death rate of older dependent offspring was much higher, at least $83 \%$. Ten out of 12 females captured that were carrying young $<55$ days old did not have an additional lactating teat, indicating they had lost an infant late in its pouch life, or after it had left the pouch but was still suckling.

\section{Discussion}

Our results indicate that the reintroduction of $O$. fraenata to Avocet Nature Refuge in 2001-2005 is at risk of failure, in contrast with the 1996-1998 reintroduction to Idalia National Park, which appears to have succeeded (Table 3; Pople et al., 2001). The population at Avocet was a tenth of the size of that of Idalia National Park after 3 years, and the mean estimate of population size on Avocet Nature Refuge (c. 40) was considerably smaller than expected given the release of 166 animals since 2001.

Population size estimates from some trapping sessions had large confidence intervals. This is probably because of individual heterogeneity in capture probabilities, small sample sizes in each trapping session, and the fact that capture effort was uneven between 2005 and early 2008 (White et al., 1982). For population size estimates of $<100$ to be reliable White et al. (1982) suggested that capture 
TABLE 2 Relative support for models of survival of $O$. fraenata at Avocet Nature Refuge: model selection using the quasi-Akaike information criterion adjusted for small sample sizes. Support for the four candidate models is shown. Phi = probability of survival, $p=$ probability of capture, $(\mathrm{t})=$ time dependence, $()=$. constant. The model with the best support (with quasi-Akaike weight and model likelihood close to 1 ) is that with time dependence in both survival and capture probability, in bold.

\begin{tabular}{|c|c|c|c|c|c|c|}
\hline Model & QAIC $\Delta$ & QAICc & QAICc weight & Likelihood & Parameters & QDeviance \\
\hline$[\mathrm{Phi}(\mathrm{t}) \mathrm{p}(\mathrm{t})]$ & 378 & $\mathbf{0}$ & 0.9998 & 1 & 13 & 117 \\
\hline$[\mathrm{Phi}(\mathrm{t}) \mathrm{p}()]$. & 394 & 17 & 0.0002 & 0.0002 & 8 & 146 \\
\hline$[\mathrm{Phi}(.) \mathrm{p}(\mathrm{t})]$ & 430 & 53 & 0 & 0 & 8 & 182 \\
\hline$[\operatorname{Phi}(.) \mathrm{p}()]$. & 487 & 110 & 0 & 0 & 2 & 254 \\
\hline
\end{tabular}

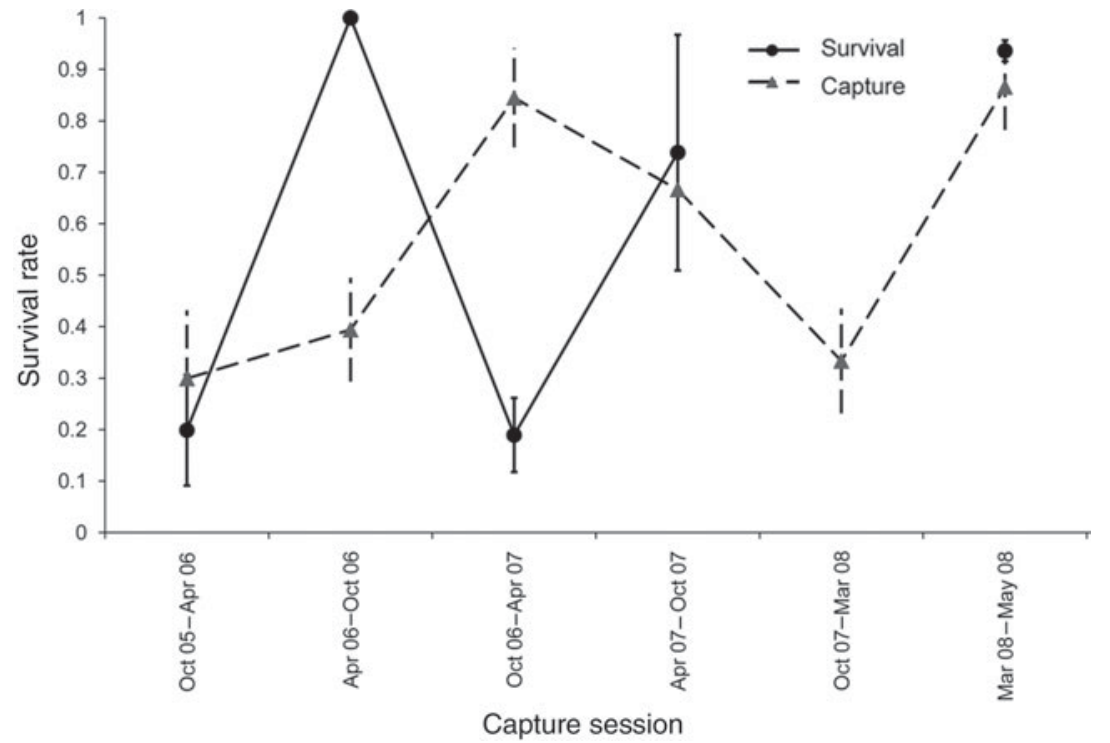

FIG. 4 Estimates of survival rates (solid line) and capture rates (dashed line) of O. fraenata at Avocet Nature Refuge during 2005-2008, with standard errors (error bars). Means are for each interval between capture sessions. Survival estimates with meaningful standard errors could not be calculated for October 2007 to March 2008 and no estimates with meaningful standard errors could be calculated for May-July 2008. The lowest survival rates were in the 6 months of the wet seasons of 2006 and 2007 (OctoberApril). The lowest capture probabilities were in the intervals April-October 2006 and October 2007 to March 2008. probabilities should be at least 0.3 . For this study, capture probabilities were adequate for sessions in which parameter estimates could be calculated ( $\mathrm{P}$ was $0.32-0.52$ ). The mean population estimate based on spotlighting in May and July 2008 agreed closely with the estimate based on trapping data. Estimates of density in this study were similar to densities calculated for the Taunton population, and for the expanding Idalia population 3 years after establishment (Table 3). There was apparently an increase in population size at Avocet in 2008. However, only the last two estimates of population size differed (the means of May and July 2008 are approximately double that of the October 2005-March 2008 estimates, with non-overlapping lower 95\% confidence limits; Fig. 3). A cause of this apparent increase might be the more intense trapping regime over a consistently larger area in 2008 compared with more erratic sampling previously.

In May and July 2008 conception failure and early loss of pouch young were rare, as in previous studies (Fisher et al., 2000, 2001). Of greater concern is our finding that only $17 \%$ of females with pouch young $<55$ days old had a concurrent young-at-foot. This indication of poor survival rate of older dependent young is similar to the rate of $18 \%$ at Taunton during a period of exceptional drought and high predation by cats in the early 1990s, when population growth was strongly negative (Fisher et al., 2000, 2001). Fisher et al. (2001) showed by matrix population modelling that $82 \%$ mortality of juveniles was enough to produce the observed population decline during drought at Taunton in the early 1990s. Juvenile survival is expected to be four or more times as high in a healthy population; in two previous studies in which the population was increasing under favourable rainfall conditions (Taunton in 1997 and Idalia in 19961999), the proportion of females breeding at capacity averaged 0.75 , four times the rate in this study (0.17; Table 3).

As in the 1993-1994 drought at Taunton National Park (Scientific) (Fisher et al., 2001), drought is likely to have had a direct detrimental effect on breeding success and adult survival in 2002-2004. However, juvenile survival was poor in 2008 despite above average rainfall and good body condition of mothers, suggesting that predation was the cause of mortality in this year. Survival of adults was also periodically very low even after this drought (corresponding to an annual survival rate of $18 \%$ in the wet seasons of 2006 and 2007; Fig. 4, Table 2). Foxes and cats are potential predators of juveniles. Fisher et al. (2001) showed that dingoes are most likely to target adult wallabies. At Taunton predation by cats particularly affects juvenile O. fraenata 
TABLE 3 Comparison of indicators of population size and density and proportion of females breeding at capacity of $O$. fraenata at Avocet Nature Refuge and Idalia National Park 3-4 years after reintroductions, and Taunton National Park (Scientific) in the 199os. Population density at Idalia National Park is based on an area of c. $40 \mathrm{~km}^{2}$ used by O. fraenata in 1999 (according to Fig. 2 of Pople et al., 2001). There was a severe drought at Taunton National Park (Scientific) in 1993-1994 and average rainfall in 1995-1997. Rainfall at Idalia National Park in 1996-1999 was above average. Populations at Idalia in 1996-1999 and at Taunton in 1997 were expanding and in 1994 were declining. The proportion of females breeding at capacity is the proportion with a pouch young $<55$ days old and a second lactating teat, indicating that the female has a surviving young-at-foot. Data are from this study and Fisher et al. (2000, 2001) and Pople et al. (2001).

\begin{tabular}{|c|c|c|c|}
\hline Site \& year & $\begin{array}{l}\text { Approximate } \\
\text { population size }\end{array}$ & $\begin{array}{l}\text { Approximate } \\
\text { population } \\
\text { density }\left(\mathrm{km}^{-2}\right)\end{array}$ & $\begin{array}{l}\text { Proportion of females } \\
\text { breeding at capacity }\end{array}$ \\
\hline Avocet Nature Refuge 2008 & 40 (166 released) & $8-39$ & 0.17 \\
\hline Idalia National Park 1996-1999 & 400 (133 released $)$ & 10 & $0.65-0.92$ \\
\hline Taunton National Park 1994-1997 & 83 (main site), 200 overall & $12-32$ & 0.71 (1997), 0.18 (1994) \\
\hline
\end{tabular}

that have recently begun to leave the pouch, dependent young-at-foot, and subadults (Fisher et al., 2000, 2001; Fisher \& Goldizen, 2001).

Predation by feral cats and introduced red foxes is the main cause of the high rate of translocation/reintroduction failure in threatened Australian mammals (Short et al., 1992; Richards \& Short, 2003). Cats were frequently seen at Avocet, and have been responsible for extinctions and reintroduction failures of other small populations of smallbodied macropods of inland open woodland habitats in eastern Australia, including the mala Lagorchestes hirsutus (Lundie-Jenkins, 1998) and brush-tailed bettong Bettongia penicillata (Priddel \& Wheeler, 2004). Cats have been implicated in declines of wild $O$. fraenata during droughts (Fisher et al., 2001). The failed translocation of brush-tailed bettongs (Priddel \& Wheeler, 2004) also occurred during a drought. It failed after 1 year, mainly because of predation by feral cats on both adults and young-at-foot, and poor condition of animals.

Consistent with the preference of this species for brigalow forest at Idalia and Taunton, we never saw or trapped O. fraenata $>200 \mathrm{~m}$ from an area of c. $2 \mathrm{~km}^{2}$ of dense brigalow woodland adjacent to the release sites at Avocet. Other areas of apparently suitable brigalow forest exist within the Refuge but the animals have not dispersed into these. Lack of dispersal at Avocet is consistent with behaviour of O. fraenata at Taunton and Idalia National Parks in the medium and long term. There is strong genetic structure in wild $O$. fraenata between parts of Taunton that are $<5 \mathrm{~km}$ apart, and radio-tracking of juveniles has revealed no long distance movements in either sex, and thus reluctance to disperse away from patches of brigalow habitat may be characteristic of the species (Fisher, 1998; Pople et al., 2001; Sigg, 2004, 2006). One reason for the greater population growth at Idalia could therefore be the larger area of continuous brigalow regrowth and associated vegetation at the release site there (c. $40 \mathrm{~km}^{2}$ compared with $2 \mathrm{~km}^{2}$ at Avocet, and c. $5 \mathrm{~km}^{2}$ at the main site at Taunton).
A major cause of historical decline for O. fraenata is predation by feral cats and, especially, foxes (Gordon \& Lawrie, 1980). Translocations and reintroductions are more likely to fail if factors that caused declines are not dealt with (Wolf et al., 1996, 1998). At Idalia intensive baiting in the release area and a surrounding buffer zone and regular predator monitoring occur and there is therefore little or no predation on O. fraenata (Pople et al., 2001). At Avocet Nature Refuge there is incidental removal of cats and foxes but no intensive control.

The small number of animals in each release at Avocet might have contributed to the relatively poor population growth in comparison with Idalia. Species-specific modelling has shown that even with very low predation rates releases of $<50 \quad$ O. fraenata are more likely to fail (McCallum et al., 1995). The mean size of groups released at Avocet was 12 whereas at Idalia 20-60 were released at a time (Pople et al., 2001).

A further major difference between the two reintroductions was the selection of animals for release, which is also a predictor of translocation success (Pople et al., 2001; Robert et al., 2004; Letty et al., 2007). The reintroduction at Idalia was an experiment to compare the success of captive and wild-bred wallabies. Wild-born individuals had higher survival (Pople et al., 2001). All of the animals released on Avocet were captive-bred and many of them had been in poor health prior to release.

We conclude that the reintroduction of $O$. fraenata to Avocet Nature Refuge is not yet self-sustaining and is at risk of failing. We suggest that future reintroductions will have the best chance of success if they occur in non-drought years, at sites with large, non-fragmented areas of brigalow forest, involve the release of large groups together, and are accompanied by intensive, long-term baiting to control introduced predators. If successful, this reintroduction to Avocet Nature Refuge will potentially improve the conservation of $O$. fraenata by increasing the number of independent populations in high quality brigalow forest habitat. We suggest that the chance of long-term success at 
this Refuge will improve if a partnership with government conservation agencies provides funding for more intensive predator baiting.

\section{Acknowledgements}

We thank Hugo Spooner and his family for generosity and practical help during fieldwork and for access to Avocet Nature Refuge. We are grateful for help from Simon Blomberg, Fiachra Kearney, Yiwei Wang and Janelle Lowry. This work was funded by a grant from the Foundation for National Parks and Wildlife.

\section{References}

Armstrong, D.P. \& Seddon, P.J. (2008) Directions in reintroduction biology. Trends in Ecology \& Evolution, 23, 20-25.

Bom (Bureau of Meteorology) (2003) Rainfall Deficiencies Intensify. Australian Government Bureau of Meteorology Archive. Http://www.bom.gov.au/climate/drought/archive/20030204.shtml [accessed 8 March 2011].

Evans, M. (1992) The bridled nailtail wallaby: ecology and management. MSc thesis, University of New England, Armidale, Australia.

Fischer, J. \& Lindenmayer, D.B. (2000) An assessment of the published results of animal relocations. Biological Conservation, 96, $1-11$.

FISHER, D.O. (1998) Behavioural ecology and demography of the bridled nailtail wallaby, Onychogalea fraenata. $\mathrm{PhD}$ thesis, The University of Queensland, St Lucia, Australia.

FISHER, D.O. (1999) Offspring sex-ratio variation in the bridled nailtail wallaby, Onychogalea fraenata. Behavioral Ecology \& Sociobiology, 45, 411-419.

Fisher, D.O., Blomberg, S.P. \& Hoyle, S.D. (2001) Mechanisms of drought-induced population decline in an endangered wallaby. Biological Conservation, 102, 107-115.

Fisher, D.O., Blomberg, S.P. \& Owens, I.P.F. (2003) Extrinsic versus intrinsic factors in the decline and extinction of Australian marsupials. Proceedings of the Royal Society of London. Series B, Biological Sciences, 270, 1801-1808.

Fisher, D.O. \& Goldizen, A.W. (2001) The maternal care and infant behaviour of the bridled nailtail wallaby. Journal of Zoology, 255, 321-330.

Fisher, D.O., Hoyle, S.D. \& Blomberg, S.P. (2000) Population dynamics and survival of an endangered wallaby: a comparison of four methods. Ecological Applications, 10, 901-910.

Gordon, G. \& LAwrie, G.C. (1980) The rediscovery of the bridled nailtailed wallaby, Onychogalea fraenata (Gould) (Marsupialia: Macropodidae) in Queensland. Australian Wildlife Research, 7, 339-345.

Hendrikz, J.K. \& Johnson, P.M. (1998) Development of the bridled nailtail wallaby, Onychogalea fraenata, and age estimation of the pouch young. Wildlife Research, 26, 239-249.

IUCN (2010) IUCN Red List of Threatened Species v. 2010.4. Http://www.iucnredlist.org/ [accessed 1 June 2011].

Johnson, C.N. (2006) Australia's Mammal Extinctions: A 50,00o Year History. Cambridge University Press, Cambridge, UK.

Johnson, P.M. (1997) Reproduction in the bridled nailtail wallaby, Onychogalea fraenata Gould (Marsupialia: Macropodidae), in captivity. Wildlife Research, 24, 411-415.
LAPIDGE, S.J. (2006) Reintroduction biology of yellow-footed rock wallabies. PhD thesis, The University of Sydney, Sydney, Australia.

Letty, J., Marchandeau, S. \& Aubineau, J. (2007) Problems encountered by individuals in animal translocations: lessons from field studies. Ecoscience, 14, 420-431.

Lundie-Jenkins, G. (1998) Reintroduction of the mala to Aboriginal land of the Tanami desert in the Northern Territory. PhD thesis, University of New England, Armidale, Australia.

Lundie-Jenkins, G. \& Lowry, J. (2005) Bridled Nailtail Wallaby Recovery Plan 2005-2009, Environmental Protection Agency, Queensland, and Environment Australia, Brisbane, Australia.

McCallum, H., Timmers, P. \& Hoyle, S. (1995) Modelling the impact of predation on reintroductions of bridled nailtail wallabies. Wildlife Research, 22, 163-171.

McKnight, M. (2008) Onychogalea fraenata. In IUCN Red List of Threatened Species. v. 2010.4. Http://www.iucnredlist.org [accessed 2 June 2011].

OLD, J.M., Lowry, J. \& YounG, L.J. (2009) Scrub-itch mite infestation in the endangered bridled nailtail wallaby. Australian Veterinary Journal, 87, 338-341.

Pople, A.R., Lowry, J., Lundie-Jenkins, G., Clancy, T.F., McCallum, H.I., SigG, D. et al. (2001) Demography of bridled nailtail wallabies translocated to the edge of their former range from captive and wild stock. Biological Conservation, 102, 285-299.

Priddel, D. \& Wheeler, R. (2004) An experimental translocation of brush-tailed bettongs (Bettongia penicillata) to western New South Wales. Wildlife Research, 31, 421-432.

R Development Core Team (2009) R v. 2.10.0: A Language and Environment for Statistical Computing. R Foundation for Statistical Computing, Vienna, Austria. Http://www.R-project.org [accessed 1 October 2009].

Richards, J.D. \& Short, J. (2003) Reintroduction and establishment of the western barred bandicoot Perameles bougainville (Marsupialia: Peramelidae) at Shark Bay, Western Australia. Biological Conservation, 109, 181-195.

Robert, A., Sarrazin, F., Couvet, D. \& Legendre, S. (2004) Releasing adults versus young in reintroductions: interactions between demography and genetics. Conservation Biology, 18, $1078-1087$.

Seddon, P.J. (1999) Persistence without intervention: assessing success in wildlife reintroductions. Trends in Ecology \& Evolution, 14,503 .

Seddon, P.J., Armstrong, D.P. \& Maloney, R.F. (2007) Developing the science of reintroduction biology. Conservation Biology, 21, 303-312.

Short, J., Bradshaw, S.D., Giles, J., Prince, R.I.T. \& Wilson, G.R. (1992) Reintroduction of macropods (Marsupialia: Macropodoidea) in Australia-a review. Biological Conservation, 62, 189-204.

SIGG, D.P. (2004) Population genetics and mating system in the single remnant and translocated populations of the endangered bridled nailtail wallaby, Onychogalea fraenata. $\mathrm{PhD}$ thesis, University of Queensland, Brisbane, Australia.

SIGG, D.P. (2006) Reduced genetic diversity and significant genetic differentiation after translocation: comparison of the remnant and translocated populations of bridled nailtail wallabies (Onychogalea fraenata). Conservation Genetics, 7, 577-589.

Tierney, P.J. (1985) Habitat and ecology of the bridled nailtail wallaby, Onychogalea fraenata, with implications for management. MAppSc thesis, Queensland Institute of Technology, Brisbane, Australia. 
Veltman, C.J., Nee, S. \& Crawley, M.J. (1996) Correlates of introduction success in exotic New Zealand birds. American Naturalist, 147, 542-557.

White, G.C., Anderson, D.R., Burnham, K.P. \& Otis, L. (1982) Capture-Recapture and Removal Methods for Sampling Closed Populations. Los Alamos National Laboratory, Los Alamos, USA.

White, G.C. \& Burnham, K.P. (1997) Program Mark-Survival Estimation from Populations of Marked Animals. Colorado State University, Fort Collins, USA.

Wolf, C.M., Garland, T. \& Griffith, B. (1998) Predictors of avian and mammalian translocation success: reanalysis with phylogenetically independent contrasts. Biological Conservation, $86,243-255$.
Wolf, C.M., Griffith, B., Reed, C. \& Temple, S.A. (1996) Avian and mammalian translocations: update and reanalysis of 1987 survey data. Conservation Biology, 10, 1142-1154

\section{Biographical sketches}

LisA KINGSLEY's research interests are in the conservation of threatened wildlife, and invasive species within island ecosystems. ANNE GOLDIZEN's research focuses on animal behaviour and conservation biology, in particularly the social structures of mammals. DIANA FISHER is a mammal ecologist with research interests in sexual selection, life history evolution, and the causes and detection of extinction, particularly in marsupials. 